\title{
ИММУНИТЕТ К COVID-19 И ВОПРОСЫ ПРОВЕДЕНИЯ СКРИНИНГОВЫХ ИССЛЕДОВАНИЙ АНТИТЕЛ K SARS-COV-2
}

Н. А. Маянский

Российский национальный исследовательский медицинский университет имени Н. И. Пирогова, Москва, Россия

B работе кратко представлены известные данные об иммунном ответе на SARS-CoV-2, а также проанализированы возможности и ограничения серологического тестирования на антивирусные антитела, которые следует учитывать при планировании популяционных исследований и интерпретации их результатов.

Ключевые слова: COVID-19, SARS-CoV-2, иммунитет, антитела, скрининг

Вклад авторов: Н. А. Маянский - анализ литературы и написание текста.

$\bowtie$ Для корреспонденции: Николай Андреевич Маянский

ул. Островитянова, д. 1, г. Москва, 117997; mayanskiy.nikolay@gmail.com

Статья получена: 01.06.2020 Статья принята к печати: 15.06.2020 Опубликована онлайн: 23.06.2020

DOI: $10.24075 /$ vrgmu.2020.035

\section{IMMUNITY TO COVID-19 AND ISSUES OF SCREENING FOR SARS-COV-2 ANTIBODIES}

\author{
Mayanskiy NA $\square$
}

Pirogov Russian National Research Medical University, Moscow, Russia

\begin{abstract}
This paper briefly presents the known data on the immune response to SARS-CoV-2, and also analyzes the possibilities and limitations of serological testing for
\end{abstract} antibodies that should be accounted for when planning population studies and interpreting their results.

Keywords: COVID-19, SARS-CoV-2, immunity, antibodies, screening

Author contribution: Mayanskiy NA — literature analysis, text authoring.

$\triangle$ Correspondence should be addressed: Nikolay A. Mayanskiy

Ostrovityanova, 1, Moscow, 117997; mayanskiy.nikolay@gmail.com

Received: 01.06.2020 Accepted: 15.06.2020 Published online: 23.06.2020

DOI: 10.24075/brsmu.2020.035

Развивающаяся пандемия COVID-19, вызванная коронавирусом SARS-CoV-2, носит беспрецедентный характер в современной истории. SARS-CoV-2 быстро распространился по всему миру, поразил более 5 млн, вызвав гибель более 300 тыс. человек (данные ВОЗ на 25 мая 2020 г.) [1], драматически изменил уклад жизни во многих странах, угрожая дальнейшими экономическими потрясениями. Реакция научного сообщества на это событие также отличается скоростью и размахом. Ведущие мировые журналы публикуют «с колес» самые последние данные о возбудителе и его воздействии на организм, подходах к лечению и принципах сдерживания распространения вируса. Эти исследования позволили в кратчайшие сроки разработать инструменты для выявления PHK SARS-CoV-2 и тестирования антивирусных антител. В настоящей публикации кратко представлены известные данные об иммунном ответе на SARS-CoV-2, а также проанализированы возможности и ограничения серологического тестирования на антивирусные антитела, которые следует учитывать при планировании популяционных исследований и интерпретации их результатов.

\section{Иммунный ответ на инфекцию SARS-CoV-2}

Накопленная к настоящему времени информация позволяет с определенной уверенностью говорить о том, что иммунный ответ на инфекцию SARS-CoV-2 протекает по типовому сценарию. У большинства инфицированных SARS-CoV-2 специфичные антитела различных классов появляются через 1-2 недели от начала симптомов [2]. В одном из исследований к 5-7 дню они были выявлены у 40-55\% пациентов, госпитализированных по поводу
COVID-19, а через 17-19 дней обнаруживались у 100\% пациентов [3]. При этом сероконверсия (т. е. появление специфичных антител в сыворотке) сопровождалась нарастанием титра антител в 2-4 раза за время наблюдения (до 27 дня от начала симптомов). По другим данным, сероконверсия у инфицированных SARS-CoV-2 с наличием симптомов происходит в среднем через 10-15 дней [4]. Важно и то, что у большинства пациентов, перенесших COVID-19, в том числе в легкой форме, появляются специфичные функциональные, т. е. вируснейтрализующие антитела, которые обеспечивают эффективный иммунитет. Через две недели от начала симптомов такие антитела были обнаружены у 94\% пациентов с COVID-19 [5].

Параллельно с антительным ответом активно вырабатывается клеточный иммунитет к SARS-CoV-2. В течение 2-4 недель после инфицирования формируется пул вирусспецифичных Т-лимфоцитов [7, 8]. Предполагается, что CD4- и CD8-Т-лимфоциты памяти смогут обеспечить надежный иммунитет от реинфекции SARS-CoV-2 для индивидов, у которых не выявлены антитела.

На данном этапе развития пандемии пока недостаточно данных о длительности иммунитета против SARS-CoV-2. Представление об этом можно получить из проведенных ранее исследований родственных коронавирусов MERSCoV и SARS-CoV-1, а также сезонных коронавирусов. Tак, после инфекции SARS-CoV-1 концентрация IgG оставалась высокой на протяжении 4-5 месяцев, а затем в течение 2-3 лет постепенно снижалась, при этом до 90\% переболевших сохраняли вируснейтрализующие антитела через 2,5 года. Схожим образом развивался антительный ответ при MERS-CoV-инфекции с сохранением антител у выздоровевших до 34 месяцев $[4,6]$. 
Открытым остается вопрос о возможности повторного заражения SARS-CoV-2. Подтвержденных случаев реинфицирования SARS-CoV-2 пока описано не было. Исследование, проведенное на приматах, показало, что перенесенная SARS-CoV-2-инфекция предотвращала реинфицирование этим вирусом [6]. Не описаны случаи повторного заражения SARS-CoV-1 и MERS-CoV. Нередки повторные инфицирования сезонными коронавирусами, которые протекают в виде нетяжелых острых респираторных заболеваний. Здесь реинфекция может быть связана с быстрым угасанием протективного иммунитета или встречей с новым серовариантом вируса [4, 6].

\section{Сероэпидемиология COVID-19}

Пока большинство исследований по сероэпидемиологии COVID-19 ограничено когортами госпитализированных пациентов и заболевших с симптомами инфекции. Не исключено, что у лиц, перенесших инфицирование без симптомов или с минимальными симптомами, динамика выработки антител, как и характеристики постинфекционного иммунитета, могут выглядеть подругому [9]. Сообщения различной степени достоверности о частоте бессимптомной (или субклинической) сероконверсии в тех или иных территориальных или профессиональных популяциях встречаются в различных средствах массовой информации, вместе с тем научных публикаций на эту тему пока крайне мало. Серологическое обследование, проведенное среди жителей Лос-Анджелеса с целью оценить кумулятивную заболеваемость COVID-19, показало наличие IgG и/или IgM антител у 35 (4,65\%) из 863 обследованных [10]. При этом у 10 (29\%) из 35 лиц с положительными антителами в течение последних двух месяцев отсутствовали какие-либо симптомы ОРВИ, что могло указывать на сероконверсию в результате бессимптомно перенесенной SARS-CoV-2инфекции. Возможность субклинической сероконверсии была продемонстрирована в небольшом исследовании, показавшем появление анти-SARS-CoV-2 IgM и/или IgG через 21 день после контакта с зараженным COVID-19 пациентом у 3 (23\%) из 13 пациентов и 11 (44\%) из 25 сотрудников амбулаторного диализного центра в США, причем у большинства антителопозитивных обследованных (у 2 из 3 пациентов и 9 из 11 сотрудников) симптомы, подобные коронавирусным, отсутствовали [11].

\section{Проблемы серологического тестирования анти-SARS-CoV-2}

Серологические тесты на антитела к SARS-CoV-2, несомненно, могут быть чрезвычайно полезны для диагностики инфекции, исследования популяционного иммунитета, оценки ответа на вакцинацию и других задач. В то же время следует не только использовать возможности, но и осознавать ограничения серологических тестов. Предостережения по поводу нерационального применения серологического тестирования на анти-SARSCoV-2 с использованием несовершенных тест-систем (которых сейчас большинство) и без критической оценки результатов были высказаны в целой серии публикаций уважаемых научных журналов [6, 9, 12-14].

Как и любое серологическое исследование, тест на анти-SARS-CoV-2 неизбежно будет давать определенную долю ошибочных (ложноположительных и ложноотрицательных) результатов. Очевидно, что их число будет зависеть от аналитических характеристик тест-системы, таких как чувствительность (способность выявлять носителей антител; доля истинно положительных результатов) и специфичность (избирательность теста; доля истинно отрицательных результатов).

Показатели чувствительности и специфичности, достигающие 90-95\%, нередко вводят в заблуждение, и их интерпретируют как низкую вероятность ошибки, соответственно 5-10\%, которой можно просто пренебречь. Однако не следует забывать о том, что число ошибочных результатов будет меняться в зависимости от частоты носительства антител в той или иной популяции. Часто этот факт игнорируют, что ведет к неточной интерпретации результатов. Проиллюстрируем это на примерах. Допустим, у нас имеется тест-система с заявленной чувствительностью и специфичностью 95\%. С ее помощью мы исследуем: 1) популяцию переболевших COVID-19 (ожидаемая частота носительства антител 90\%); 2) популяцию не болевших COVID-19 и не имевших симптомов ОРВИ в последние 2 месяца (ожидаемая частота носительства антител 5\%). Для оценки достоверности результата теста рассчитывают положительное прогностическое значение (ППЗ), т. е. вероятность того, что положительный результат теста истинно положителен, по формуле [14]:

ППЗ $=\frac{\text { Чувствительность } \times \text { Частота }}{\text { Чувствительность } \times \text { Частота }+(1-\text { Специфичиность }) \times(1-\text { Частота })}$

Для первой популяции (переболевших COVID-19) мы получим ППЗ = 0,99, т. е. вероятность того, что при положительном результате теста у индивида действительно будут присутствовать антитела, составляет 99\%. Радикально подругому будет выглядеть ситуация во второй гипотетической популяции, для которой значение ППЗ (отметим: при тех же показателях чувствительности и специфичности тест-системы) будет только 50\%. Так, избирательность тест-системы со специфичностью в 95\% оказывается недостаточной для популяции с низкой частотой антител и дает ложноположительные результаты в половине (!) случаев.

Таким образом, судить о «высоте» чувствительности и специфичности тест-системы следует в зависимости от того, какую популяцию планируется исследовать, а результаты тестирования необходимо интерпретировать с поправкой на возможную ошибку. Несложные расчеты показывают, что для достижения ППЗ > 80\% в популяции с частотой встречаемости антител 5\% тест-система должна иметь специсичность > 99\%.

K настоящему времени на рынке появились десятки тест-систем различных производителей для определения антител к SARS-CoV-2. Их продвижение сопровождают активные маркетинговые кампании, декларирующие точность и надежность тестирования. Не все производители открыто сообщают об аналитических характеристиках своих изделий, некоторые, вероятно, не имеют о них представления, так как не проводили нужных исследований [9]. Использование таких ненадежных тестов в период пандемии может быть опасно как для конкретного человека, так и для популяции в целом. Решения, связанные с вопросами допуска к работе медицинского персонала, смягчения/усиления ограничительных мер, а также стигматизация «безантительных» лиц и, наоборот, полная индульгенция индивидам с «антителами» к SARS-CoV-2 вплоть до выдачи так называемых «иммунологических паспортов» на основе единственного исследования, обладающего неопределенной достоверностью, могут привести к серьезным последствиям [9, 13]. 
Кроме того, «массовость» серологического тестирования должна быть разумной, тестировать всю популяцию непрактично и не нужно. Например, есть методические указания Роспотребнадзора, где детально прописан порядок организации и проведения серологического мониторинга состояния коллективного иммунитета к вакциноуправляемым инфекциям [15]. В них описаны индикаторные репрезентативные группы, подлежащие тестированию, кратность их обследования и т. д. Скрининг анти-SARS-CoV-2-антител должен быть четко спланирован, чтобы результаты, полученные на сравнительно небольших выборках, могли дать надежное представление о ситуации с коллективным иммунитетом как по популяции в целом, так и в отдельных группах повышенного риска (в частности, среди медицинских работников) или уязвимых группах населения (пожилые люди, пациенты с хроническими заболеваниями и др.).

В связи с высказанными соображениями гигантские масштабы скрининга населения на анти-SARS-CoV-2, начатого в мае 2020 г. в Москве, с планируемым охватом 3-6 млн человек, стоимость которого может составить 0,5-1 млрд руб. [16], вызывают по меньшей мере недоумение. Заметим, что тест-система, используемая для этого проекта, имеет специфичность 95,38\% ${ }^{1}$, что явно недостаточно для использования в популяции с низкой частотой антител, о чем говорилось выше. C высокой долей уверенности можно утверждать, что в настоящий момент жители Москвы, пробывшие в условиях самоизоляции почти два месяца, составляют именно такую популяцию. Даже если предположить, что реальная доля серопозитивных лиц составляет 10\%, то тест с указанной специсичностью будет давать > 30\% ложноположительных результатов.

\section{ВЫВОДЫ}

Массовое тестирование лиц, не болевших COVID-19 (т. е. популяции с низкой частотой анти-SARS-CoV-2), может генерировать большое число ложноположительных результатов, значительно превышающее число истинно положительных результатов. Размер выборки для таких исследований необходимо планировать по принципу разумной достаточности, а данные следует интерпретировать с учетом аналитических характеристик тест-систем, используемых для определения антител. Эти характеристики должны быть публично доступны и проверяемы. В противном случае, широкое использование несовершенных серологических тестов может стать источником серьезных ошибок при принятии медицинских и управленческих решений.

1 Это значение указано в решении Клинического комитета по COVID-19 Департамента здравоохранения г. Москвы от 12.05 .2020 (официально не опубликовано). Других источников об аналитических характеристиках данной тест-системы обнаружить не удалось.

\section{Литература}

1. WHO: Coronavirus disease (COVID-19). Situation Report 126. Available from: https://www.who.int/docs/default-source/ coronaviruse/situation-reports. Доступ 26 мая 2020.

2. Sethuraman N, Jeremiah SS, Ryo A. Interpreting Diagnostic Tests for SARS-CoV-2. JAMA. 2020 May 6. DOI: 10.1001/ jama.2020.8259.

3. Long QX, Liu BZ, Deng HJ, Wu GC, Deng K, Chen YK, et al. Antibody responses to SARS-CoV-2 in patients with COVID-19. Nat Med. 2020 Apr 29. DOI: 10.1038/s41591-020-0897-1.

4. Kellam P, Barclay W. The dynamics of humoral immune responses following SARS-CoV-2 infection and the potential for reinfection. J Gen Virol. 2020 May 20. DOI: 10.1099/jgv.0.001439.

5. Wu F, Wang A, Liu M, Wang Q, Chen J, Xia S, et al. Neutralizing antibody responses to SARS-CoV-2 in a COVID-19 recovered patient cohort and their implications. Preprint at medRxiv. Available from: https://doi.org/10.1101/2020.03.30.20047365.

6. Kirkcaldy RD, King BA, Brooks JT. COVID-19 and Postinfection Immunity: Limited Evidence, Many Remaining Questions. JAMA 2020 May 11. DOI: 10.1001/jama.2020.7869.

7. Melgaço JG, Azamor T, Ano Bom APD. Protective immunity after COVID-19 has been questioned: What can we do without SARSCoV-2-IgG detection? Cell Immunol. 2020 Apr 28; 353: 104114. DOI: 10.1016/j.cellimm.2020.104114.

8. Ni L, Ye F, Cheng ML, Feng Y, Deng YQ, Zhao H, et al. Detection of SARS-CoV-2-Specific Humoral and Cellular Immunity in COVID-19 Convalescent Individuals. Immunity. 2020 May 3. DOI: 10.1016/j.immuni.2020.04.023.

\section{References}

1. WHO: Coronavirus disease (COVID-19). Situation Report 126. Available from: https://www.who.int/docs/default-source/ coronaviruse/situation-reports. Доступ 26 мая 2020.

2. Sethuraman N, Jeremiah SS, Ryo A. Interpreting Diagnostic
9. Torres R, Rinder HM. Double-Edged Spike-Are SARS-CoV-2 Serologic Tests Safe Right Now? Lab Med. 2020 May 6; 51 (3): 236-8. DOI: 10.1093/labmed/Imaa025.

10. Sood N, Simon P, Ebner P, Eichner D, Reynolds J, Bendavid E, et al. Seroprevalence of SARS-CoV-2-Specific Antibodies Among Adults in Los Angeles County, California, on April 10-11, 2020. JAMA. 2020 May 18: e208279. DOI: 10.1001/jama.2020.8279.

11. Hains DS, Schwaderer AL, Carroll AE, Starr MC, Wilson AC, Amanat F, et al. Asymptomatic Seroconversion of Immunoglobulins to SARS-CoV-2 in a Pediatric Dialysis Unit. JAMA. 2020 May 14: e208438. DOl: 10.1001/jama.2020.8438.

12. Ismail AA. Serological tests for COVID-19 antibodies: Limitations must be recognized. Ann Clin Biochem. 2020 May 14: 4563220927053. DOI: 10.1177/0004563220927053.

13. Krammer F, Simon V. Serology assays to manage COVID-19. Science. 2020 May 15: eabc1227. DOI: 10.1126/science.abc1227.

14. Mathur G, Mathur S. Antibody Testing For Covid-19. Am J Clin Pathol. 2020 May 15: aqaa082. DOI: 10.1093/ajcp/aqaa082.

15. Методические указания МУ 3.1.2943-11 «Организация и проведение серологического мониторинга состояния коллективного иммунитета к инфекциям, управляемым средствами специфической профилактики (дифтерия, столбняк, коклюш, корь, краснуха, эпидемический паротит, полиомиелит, гепатит В)».

16. Available from: https://vademec.ru/news/2020/05/25/mgfomsopredelil-stoimost-provedeniya-testa-na-antitela-k-covid-19. Доступ 26 мая 2020.

Tests for SARS-CoV-2. JAMA. 2020 May 6. DOI: 10.1001/ jama.2020.8259.

3. Long QX, Liu BZ, Deng HJ, Wu GC, Deng K, Chen YK, et al. Antibody responses to SARS-CoV-2 in patients with COVID-19. 
Nat Med. 2020 Apr 29. DOI: 10.1038/s41591-020-0897-1.

4. Kellam P, Barclay $W$. The dynamics of humoral immune responses following SARS-CoV-2 infection and the potential for reinfection. J Gen Virol. 2020 May 20. DOI: 10.1099/jgv.0.001439.

5. Wu F, Wang A, Liu M, Wang Q, Chen J, Xia S, et al. Neutralizing antibody responses to SARS-CoV-2 in a COVID-19 recovered patient cohort and their implications. Preprint at medRxiv. Available from: https://doi.org/10.1101/2020.03.30.20047365.

6. Kirkcaldy RD, King BA, Brooks JT. COVID-19 and Postinfection Immunity: Limited Evidence, Many Remaining Questions. JAMA. 2020 May 11. DOI: 10.1001/jama.2020.7869.

7. Melgaço JG, Azamor T, Ano Bom APD. Protective immunity after COVID-19 has been questioned: What can we do without SARSCoV-2-IgG detection? Cell Immunol. 2020 Apr 28; 353: 104114. DOI: 10.1016/j.cellimm.2020.104114.

8. Ni L, Ye F, Cheng ML, Feng Y, Deng YQ, Zhao H, et al. Detection of SARS-CoV-2-Specific Humoral and Cellular Immunity in COVID-19 Convalescent Individuals. Immunity. 2020 May 3. DOI: 10.1016/j.immuni.2020.04.023.

9. Torres R, Rinder HM. Double-Edged Spike-Are SARS-CoV-2 Serologic Tests Safe Right Now? Lab Med. 2020 May 6; 51 (3): 236-8. DOI: 10.1093/labmed/Imaa025.

10. Sood N, Simon P, Ebner P, Eichner D, Reynolds J, Bendavid E, et al. Seroprevalence of SARS-CoV-2-Specific Antibodies Among Adults in Los Angeles County, California, on April 10-11, 2020. JAMA. 2020 May 18: e208279. DOI: 10.1001/jama.2020.8279.

11. Hains DS, Schwaderer AL, Carroll AE, Starr MC, Wilson AC, Amanat $F$, et al. Asymptomatic Seroconversion of Immunoglobulins to SARS-CoV-2 in a Pediatric Dialysis Unit. JAMA. 2020 May 14: e208438. DOI: 10.1001/jama.2020.8438.

12. Ismail AA. Serological tests for COVID-19 antibodies: Limitations must be recognized. Ann Clin Biochem. 2020 May 14: 4563220927053. DOI: 10.1177/0004563220927053.

13. Krammer F, Simon V. Serology assays to manage COVID-19. Science. 2020 May 15: eabc1227. DOI: 10.1126/science. abc1227.

14. Mathur G, Mathur S. Antibody Testing For Covid-19. Am J Clin Pathol. 2020 May 15: aqaa082. DOI: 10.1093/ajcp/aqaa082.

15. Metodicheskie ukazaniay MU 3.1.2943-11 "Organizatsiya b provedenie serologicheskogo monitoring sostoyaniay kollectivnogo immunitets k infectsiyam, upravlyaemym sredstavami spetsificheskoi profilaktiki (difteriya, stolbnyakm koklyush, korj, krasnukha, gepatit B)". Russian.

16. Available from: https://vademec.ru/news/2020/05/25/mgfomsopredelil-stoimost-provedeniya-testa-na-antitela-k-covid-19. Доступ 26 мая 2020. 